Characterization of polishing induced defects and hydrofluoric acid passivation effect in $\mathrm{ZnO}$

Zhichun Zhang, , V. Quemener, , C.-H. Lin, , B. G. Svensson, and, and L. J. Brillson

Citation: Appl. Phys. Lett. 103, 072107 (2013); doi: 10.1063/1.4818712

View online: http://dx.doi.org/10.1063/1.4818712

View Table of Contents: http://aip.scitation.org/toc/apl/103/7

Published by the American Institute of Physics

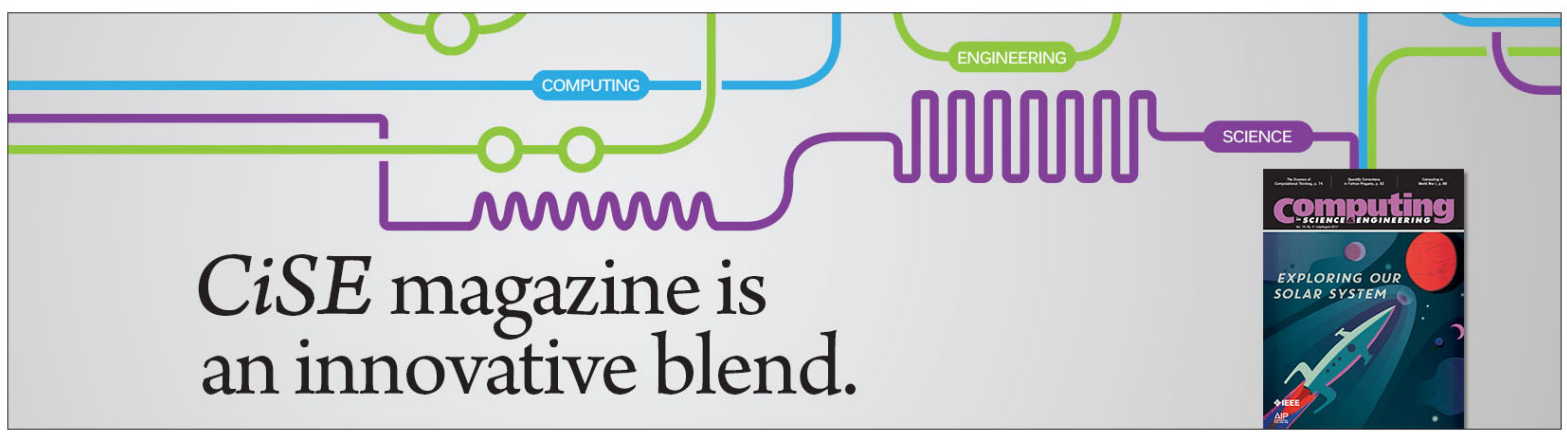




\title{
Characterization of polishing induced defects and hydrofluoric acid passivation effect in $\mathrm{ZnO}$
}

\author{
Zhichun Zhang, ${ }^{1, \text { a) }}$ V. Quemener, ${ }^{2}$ C.-H. Lin, ${ }^{1}$ B. G. Svensson, ${ }^{2}$ and L. J. Brillson ${ }^{1,3,4}$ \\ ${ }_{1}^{1}$ Department of Electrical and Computer Engineering, The Ohio State University, Columbus, Ohio 43210, USA \\ ${ }^{2}$ Department of Physics, University of Oslo, P.O. Box 1048 Blindern, N-0316 Oslo, Norway \\ ${ }^{3}$ Department of Physics, The Ohio State University, Columbus, Ohio 43210, USA \\ ${ }^{4}$ Center for Materials Research, The Ohio State University, Columbus, Ohio 43210, USA
}

(Received 21 July 2013; accepted 26 July 2013; published online 13 August 2013)

\begin{abstract}
We used depth-resolved cathodoluminescence spectroscopy and transient photovoltage spectroscopy (T-SPS) measurements to study the spatial distributions and densities of native point defects in bulk $\mathrm{ZnO}$ samples subjected to mechanical polishing and how the defects change with hydrofluoric acid (HF) etching. Mechanical polishing produces $\mathrm{Zn}$ vacancy-related defects that deplete free carriers at depths extending to $300-500 \mathrm{~nm}$, while HF etching removes/passivates these defects as well as bulk oxygen vacancy-related defects, restoring the charge carriers below the etched surface. T-SPS defect density changes with polishing/etching correlate closely with deep level transient spectroscopy densities, demonstrating the applicability of T-SPS as a non-contact quantitative defect density measurement technique. (C) 2013 AIP Publishing LLC. [http://dx.doi.org/10.1063/1.4818712]
\end{abstract}

$\mathrm{ZnO}$ is a leading candidate for next generation opto- and micro-electronics due to its high exciton binding energy, thermochemical stability, environmental compatibility, and potential applications for light emitting devices and photovoltaics. $^{1,2}$ However, because of intrinsic defects ${ }^{3,4}$ and/or various donor impurities, such as $\mathrm{Al}, \mathrm{In}, \mathrm{H},{ }^{5-7}$ controlling the electrical behavior of $\mathrm{ZnO}$ remains a fundamental, unresolved challenge. Previous research also showed the soft nature of $\mathrm{ZnO}^{8-10}$ which significantly affects the wafer handling, processing, and manufacture of $\mathrm{ZnO}$-based devices. Polishing induced damage has been investigated by cathodoluminescence (CL) ${ }^{9-15}$ photoluminescence (PL) ${ }^{16,17}$ ion channeling, ${ }^{18}$ positron annihilation spectroscopy (PAS) ${ }^{19}$ and deep level transient spectroscopy (DLTS). ${ }^{20}$ Both CL and PL research on $\mathrm{ZnO}$ demonstrated that mechanical polishing leads to surface and near surface damage, which decreases near band edge (NBE) luminescence efficiency, and forms non-radiative recombination centers (NRRCs) and intrinsic defects such as zinc vacancy $\left(\mathrm{V}_{\mathrm{Zn}}\right)$ and zinc interstitial $\left(\mathrm{Zn}_{\mathrm{i}}\right) .{ }^{10-17}$ PAS studies also show creation of dislocations and vacancy defects in the near and sub-surface region after polishing. ${ }^{19}$ Recent DLTS measurements show that mechanical polishing introduced two defect levels at 1.0 and $1.2 \mathrm{eV}$ below the conduction band edge $\mathrm{E}_{\mathrm{C}}$ whose densities subsequent hydrofluoric acid (HF) etching reduced substantially while restoring bulk carrier densities. ${ }^{20}$ While believed to be vacancy-related, the nature and spatial distribution of these defects and their removal or passivation has remained unknown.

Our previous work correlated the commonly observed $1.9-2.1 \mathrm{eV}, 2.3-2.5 \mathrm{eV}$, and $3.0 \mathrm{eV}$ luminescence peaks in $\mathrm{ZnO}$ with zinc vacancy and vacancy clusters-related (denoted $\mathrm{V}_{\mathrm{Zn}}-\mathrm{R}$ and $\left(\mathrm{V}_{\mathrm{Zn}}\right)_{\mathrm{n}}-\mathrm{R}$, respectively), oxygen vacancy (denoted $\mathrm{V}_{\mathrm{O}}$ )—related and Li substitutional on zinc vacancy (denoted $\mathrm{Li}_{\mathrm{Zn}}$ ) - related defects, respectively, based on

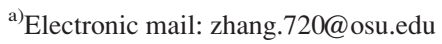

combined depth-resolved cathodoluminescence spectroscopy (DRCLS), PAS, secondary ion mass spectrometry (SIMS), surface photovoltage spectroscopy (SPS), and related surface science techniques. ${ }^{21-23}$ Hydrogen is one of the most common but important impurities during various synthesis and processes of $\mathrm{ZnO}$ and may play a role in chemical etching. $^{24,25}$ Thus acid etching could improve n-type $\mathrm{ZnO}$ conductivity by passivating compensating acceptors ${ }^{26-32}$ and/or acting as shallow donors. ${ }^{7,32-39}$

In this study, we report on the nature, depth distribution, and concentration of defects induced by mechanical polishing in single-crystal bulk hydrothermal (HT) $\mathrm{ZnO}$ and their removal and/or passivation with HF etching. DRCLS provided transition energies and density variations versus depth on a nanometer scale, while SPS provided their energy positions within the band gap and transient SPS provided their densities within the near-surface region, consistent with DLTS densities on the same samples. Polishing induced both $\mathrm{V}_{\mathrm{Zn}}-\mathrm{R}$ and $\mathrm{V}_{\mathrm{O}}-\mathrm{R}$ defects within the outer $600 \mathrm{~nm}$, while removal of $200 \mathrm{~nm}$ by etching in dilute $\mathrm{HF}$ removed $\mathrm{V}_{\mathrm{Zn}}-\mathrm{R}$ and reduced $\mathrm{V}_{\mathrm{O}}-\mathrm{R}$ defects dramatically also in the additional previously probed $400 \mathrm{~nm}$, consistent with $\mathrm{H}$ passivation. Close correspondence of defect densities deducted from t-SPS for nominal $139 \mathrm{~nm}$ depletion widths vs. DLTS demonstrate the applicability/validity of this non-contact defect density measurement technique.

Two samples with a size of $5 \times 5 \times 0.5 \mathrm{~mm}^{3}$ cut from one n-type HT- $\mathrm{ZnO}$ wafer were used in the study. They were first annealed at $1400^{\circ} \mathrm{C}$ for $1 \mathrm{~h}$ in flowing oxygen, in order to reduce the $\mathrm{Li}$ concentration from $10^{17} \mathrm{~cm}^{-3}$ range to $10^{15} \mathrm{~cm}^{-3}$ range. ${ }^{40,41}$ The samples were then mechanically polished on both sides on a rotating disc with diamond slurry using different grain sizes from $6 \mu \mathrm{m}$ to $1 / 4 \mu \mathrm{m}$ to remove $\sim 20-30 \mu \mathrm{m}$ from both sides. One of these two samples (d2) was then etched in a $2 \% \mathrm{HF}$ solution at room temperature for $2 \mathrm{~min}$, removing about $200 \mathrm{~nm}$ top layer exposed to the polishing process. ${ }^{20} \mathrm{Pd}$ Schottky contacts were deposited on the 
(0001) Zn-face of both samples. See Ref. 20 for further contact, $\mathrm{C}-\mathrm{V}$, and DLTS details.

DRCLS measurements were obtained on $\mathrm{ZnO}$ (0001) $\mathrm{Zn}$-face of $\mathrm{d} 1$ and $\mathrm{d} 2$ at $80 \mathrm{~K}$ and constant power in ultrahigh vacuum employing a JEOL 7800F UHV scanning electron microprobe with hemispherical electron analyzer and Oxford/ Gatan optical train. Monte Carlo simulation ${ }^{42}$ provides depth distributions of the electron-hole pairs generated by the incident electron beam versus $E_{B}$. For incident energy $E_{B}=1,2$, $5,6,8,10,15,20$, and $25 \mathrm{keV}$, electron-hole pair excitation peaks at depths $\mathrm{U}_{0}=7,18,72,100,160,215,530,950$, and $1500 \mathrm{~nm}$, respectively, while their maximum or Bohr-Bethe range $R_{B}$ is $\sim 3 \times$ longer.

To investigate defect energy positions and densities after polishing and HF etching, we used SPS employing an atomic force microscope (AFM) combined with Kelvin probe force microscopy (KPFM) to measure surface potential with nanometer scale spatial resolution and as a function of incident photon energy. ${ }^{43-45}$ SPS monitors changes in surface electric potential with illumination as incident photon energy $\mathrm{h} \nu$ sweeps from low to above-band-gap energies. The corresponding contact potential difference (CPD) between the illuminated surface and the KPFM tip varies with $\mathrm{h} \nu$ as n-type semiconductor band bending increases (decreases) with electron filling (emptying) of near-surface states at characteristic threshold energies. ${ }^{21,44,45}$ SPS transients typically required $\sim 100-150$ s to reach new equilibria at photothreshold onset energies corresponding to a specific defect transition.

Figure 1(a) shows the $80 \mathrm{~K}$ DRCLS spectra obtained for mechanically polished (0001) $\mathrm{ZnO}$ from near-surface $(7 \mathrm{~nm})$ to bulk $(1500 \mathrm{~nm})$ peak excitation below the free surface. Compared to the bulk, NBE intensities are nearly two orders of magnitude lower and phonon replicas typical of high crystal quality are absent in the near surface region. For CL peak (maximum range) excitation extending to $100 \mathrm{~nm}$ below the free surface, dominant deep level defect emission appears at $\sim 2.05 \mathrm{eV}$ and is evident for depth extending to $160 \mathrm{~nm}$. And Figure 1(b) shows that subsequent HF etching increases nearsurface NBE intensity by $\sim 2$ orders of magnitude with phonon replicas now evident. Emission at $\sim 2.05 \mathrm{eV}$ is absent while deep level emission at $\sim 2.4 \mathrm{eV}$ dominates at all depths.

Previously, $2.4 \mathrm{eV}$ and $2.05 \mathrm{eV}$ CL emissions were identified with $\mathrm{V}_{\mathrm{O}^{-}}$and $\mathrm{V}_{\mathrm{Zn}}-\mathrm{R}$ defects, respectively. ${ }^{21}$ Hence,
Fig. 1(a) demonstrates that mechanical polishing creates high concentrations of $\mathrm{V}_{\mathrm{Zn}}$-related defects within the outer $\sim 500 \mathrm{~nm}$. This is consistent with recent $\mathrm{PL}^{15}$ and $\mathrm{PAS}^{19}$ measurements of mechanically polished $\mathrm{ZnO}$, which showed the formation of vacancy type defects in the near surface region including $\mathrm{V}_{\mathrm{Zn}}$. Previous $\mathrm{CL}$ and $\mathrm{PL}$ of $\mathrm{ZnO}$ showed that mechanical polishing leads to subsurface damage with NBE intensity decreases, ${ }^{10,14,15}$ which our results confirm. The $\sim 2.05 \mathrm{eV}$ emissions apparent for maximum range depths of $\sim 500 \mathrm{~nm}$ are also consistent with the depletion region measured by $\mathrm{C}-\mathrm{V}$ previously of nearly $600 \mathrm{~nm}$ and with the acceptor nature of $\mathrm{V}_{\mathrm{Zn}}$-related defects, which compensate the $n$-type doping. ${ }^{20}$ Furthermore, HF etching removed only $200 \mathrm{~nm}$ of the $\sim 600 \mathrm{~nm}$ depleted thickness, yet it restored bulk carrier densities to less than $\sim 150 \mathrm{~nm}$ of the surface, ${ }^{20}$ indicating that it passivated defects within the remaining $\sim 250 \mathrm{~nm}$ or more previously depleted region. Therefore, HF etching not only removed $\mathrm{V}_{\mathrm{Zn}}-\mathrm{R}$ defects from the top $100 \mathrm{~nm}$ but also passivated $\mathrm{V}_{\mathrm{Zn}}-\mathrm{R}$ defects further into the bulk to recover the donor concentration. Hydrogen arising from the HF etch can account for this passivation by forming neutral $\mathrm{Zn}$ vacancy complexes $\mathrm{V}_{\mathrm{Zn}} \mathrm{H}_{2} \cdot{ }^{27,31,32}$ Excess $\mathrm{H}$ passivation of $\mathrm{O}$ dangling bond at $\mathrm{V}_{\mathrm{Zn}}$ can also form $\mathrm{O}-\mathrm{H}$ complexes that behave as donors. ${ }^{32,46-48}$

Figure 2 compares $\mathrm{d} 1$ and $\mathrm{d} 2$ spectra along with normalized deep level-to-NBE emission intensities I(deep level)/ $\mathrm{I}(\mathrm{NBE})$ versus depth (inset) at $\mathrm{E}_{\mathrm{B}}$ corresponding to excitation well beyond the depletion depth used in DLTS measurements on these samples. HF etching passivates the $2.4 \mathrm{eV}$ $\mathrm{V}_{\mathrm{O}}$-related defects deeper into the bulk - as much as $10 \times$ for depths extending to $900 \mathrm{~nm}$. Defect intensities for $\mathrm{d} 2$ begin rising toward bulk values at $\mathrm{U}_{0}=1500 \mathrm{~nm}$ peak excitation, indicating a finite range for the HF passivation.

DLTS measurements of $\mathrm{d} 1$ and $\mathrm{d} 2$ defect densities revealed five defect levels within the $\mathrm{ZnO}$ band gap, one of which, E5 $\left(\mathrm{E}_{\mathrm{C}}-1.0 \mathrm{eV}\right)$, post-polish $\mathrm{HF}$ etching reduced by an order of magnitude, while another, E6 $\left(\mathrm{E}_{\mathrm{C}}-1.2 \mathrm{eV}\right)$, decreased by a factor of $\sim 7 .^{20}$ The E5 level corresponds to $\mathrm{E}_{\mathrm{V}}+2.4 \mathrm{eV}$, whose optical transition is associated with $\mathrm{V}_{\mathrm{O}}-\mathrm{R}$ defects assuming negligible Franck-Condon shift. The E6 level corresponds to $\mathrm{E}_{\mathrm{V}}+2.15 \mathrm{eV}$, close to the $2.05 \mathrm{eV}$ optical transition energy for $\mathrm{V}_{\mathrm{Zn}}-\mathrm{R}$ defects. DLTS-derived concentrations for E5 in d1 and d2 were $\sim 4 \times 10^{15} \mathrm{~cm}^{-3}$ and
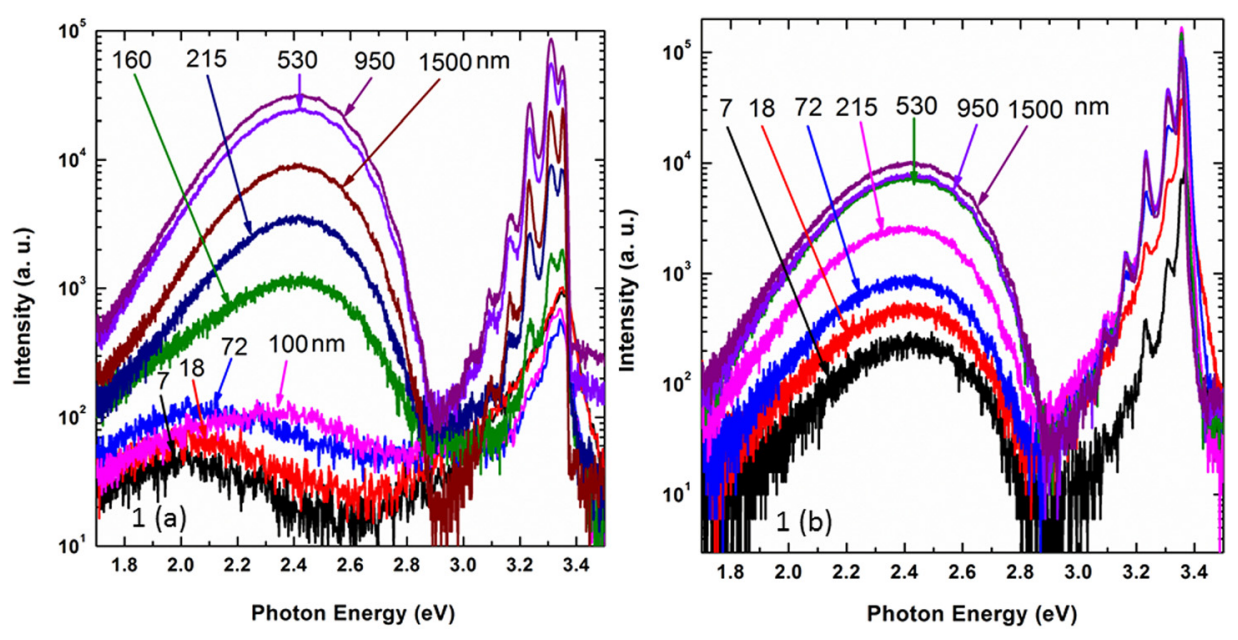

FIG. 1. $80 \mathrm{~K}$ DRCLS spectra of (0001) $\mathrm{ZnO}$ at various depth up to $1500 \mathrm{~nm}$ after (a) mechanical polishing with $6 \mu \mathrm{m}$ to $1 / 4 \mu \mathrm{m}$ diamond slurry and (b) subsequent HF etching. Mechanical polishing decreases NBE luminescence efficiency and shifts defect peak intensity from $\sim 2.4 \mathrm{eV}$ to $\sim 2.05 \mathrm{eV}$ in near-surface regions, while HF etching increases (decreases) near-surface $\operatorname{NBE}(\sim 2.05 \mathrm{eV})$ emission intensities. 


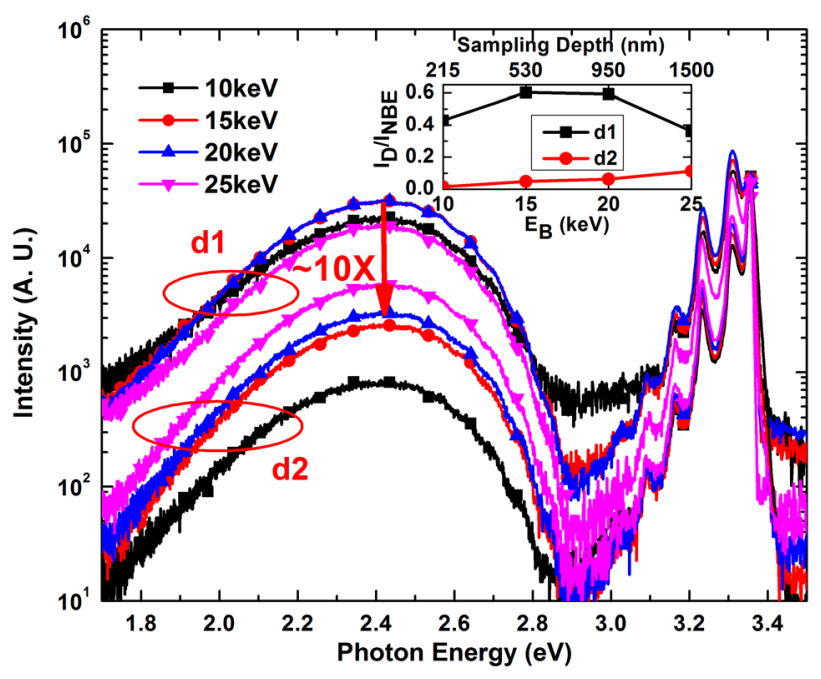

FIG. 2. $80 \mathrm{~K}$ DRCLS spectra comparison of polished $\mathrm{ZnO}$ sample $\mathrm{d} 1$ and subsequently $\mathrm{HF}$ etched $\mathrm{ZnO}$ sample $\mathrm{d} 2$. The spectra are normalized relative to $\mathrm{NBE}$ at $3.353 \mathrm{eV}$. Inset shows maximum relative deep level defect to NBE intensities versus sampling depth. HF etching decreases the deep band emission intensity by approximately an order of magnitude.

$\sim 3 \times 10^{14} \mathrm{~cm}^{-3}$, respectively, while for E6 they were $1 \times 10^{16} \mathrm{~cm}^{-3}$ and $1.5 \times 10^{15} \mathrm{~cm}^{-3}$, respectively. The E5 defect density proportions before and after HF etching are similar to those of the Fig. 2 DRCLS intensity ratios $\mathrm{I}(\sim 2.4 \mathrm{eV}) / \mathrm{I}_{\mathrm{NBE}}=\sim 0.60$ and 0.049 for $\mathrm{d} 1$ and $\mathrm{d} 2$, respectively. Similar E6 defect density proportions are consistent with the reduced $\sim 2.05 \mathrm{eV}$ intensity after HF etching.

To account for these lower defect densities and emissions, we argue that HF etching results in defect passivation by hydrogen, which has been investigated theoretically and experimentally. ${ }^{7,32-39} \mathrm{~V}_{\mathrm{O}}$ can be regarded as a deep doubledonor and interaction with $\mathrm{H}^{+}$forms the shallow donor $\mathrm{H}_{\mathrm{O}}{ }^{+}$ through the reaction, ${ }^{7}$

$$
\mathrm{V}_{\mathrm{O}}+\mathrm{H}^{+} \rightarrow \mathrm{H}^{+} \text {. }
$$

Accordingly, the reaction of Eq. (1) would increase the shallow donor concentration in the near-surface region of $\mathrm{HF}$ etched $\mathrm{ZnO}$, as reported previously. ${ }^{20}$ Hydrogen passivation of $\mathrm{V}_{\mathrm{Zn}}-\mathrm{R}$ defects also removes compensating acceptors, further increasing free carrier density. ${ }^{36}$
SPS and t-SPS provide a consistent picture with DLTS of defect levels and densities. Figures 3(a) and 3(b) show the surface photovoltage spectroscopy of polished and HF etched $\mathrm{ZnO}$ surface, respectively. The upward band bending at NBE energies of both samples indicates an n-type response $^{21,43}$ because above band-gap illumination creates free electron-hole pairs that decrease band bending and decrease surface work function. Changes in the SPS CPD slope versus hv signify threshold energies for electron photodepopulation or population of gap states. SPS spectra in Fig. 3 for (a) d1 and (b) d2 exhibit upward and downward slope changes at photo-population and depopulation threshold energies, respectively, including pairs of onsets corresponding to photo-population and depopulation of the same gap state and which sum up to $3.35 \mathrm{eV}$, the band gap energy. In Fig. 3(a), pairs include: 1.00 and $2.35 \mathrm{eV}$ corresponding to $\mathrm{V}_{\mathrm{O}}-\mathrm{R}$ defects at $\mathrm{E}_{\mathrm{C}}-1.0 \mathrm{eV}$ as well as 1.3 and $2.05 \mathrm{eV}$ corresponding to $\mathrm{V}_{\mathrm{Zn}}-\mathrm{R}$ defects at $\mathrm{E}_{\mathrm{C}}-1.3 \mathrm{eV}$, respectively. In Fig. 3(b), the 1.00 and $1.3 \mathrm{eV}$ features are reduced, while the $2.00 / 2.05 \mathrm{eV}$ features are absent, signifying reduction of the densities for these defects and consistent with our CL and DLTS results. An $\mathrm{E}_{\mathrm{V}}+2.9 \mathrm{eV}$ photo-population transition appears in both Figs. 3(a) and 3(b), consistent with a reported $\mathrm{E}_{\mathrm{C}}-0.54 \mathrm{eV}$ defect. ${ }^{20}$ The $1.6 \mathrm{eV}$ feature in both panels may be a 2nd order grating response to NBE excitation. Therefore, both CL and SPS results show that mechanical polishing followed by $\mathrm{HF}$ etching passivates $\mathrm{V}_{\mathrm{Zn}}-\mathrm{R}$ states and reduces $\mathrm{V}_{\mathrm{O}}-\mathrm{R}$ defects.

Near-surface densities of states obtained by T-SPS for these specimens provide further correspondence with reported DLTS bulk defect densities. Transient photoresponse at energies corresponding to photo-induced population and depopulation of specific states causes surface potential changes whose rates of change yield trap densities $n_{t}^{0}$ according to ${ }^{45}$

$$
n_{t}^{0}=\frac{40 \times \delta V_{s}^{1}\left(2 \varepsilon k T N_{b}\right)}{2 q\left|V_{s}^{0}\right|^{\frac{1}{2}}\left(1+\dot{V}_{s}^{1} / \dot{V}_{s}^{0}\right)},
$$

where $\delta V_{s}{ }^{1}$ is the light-induced surface potential difference, $\varepsilon$ is the $\mathrm{ZnO}$ dielectric permittivity $=8.75 \varepsilon_{0}$ along the wurtzite crystal's $c$-axis, $k$ is Boltzmann's constant, T is temperature $(\mathrm{K}), N_{b}$ is bulk electron density, which is $5 \times 10^{16} \mathrm{~cm}^{-3}$
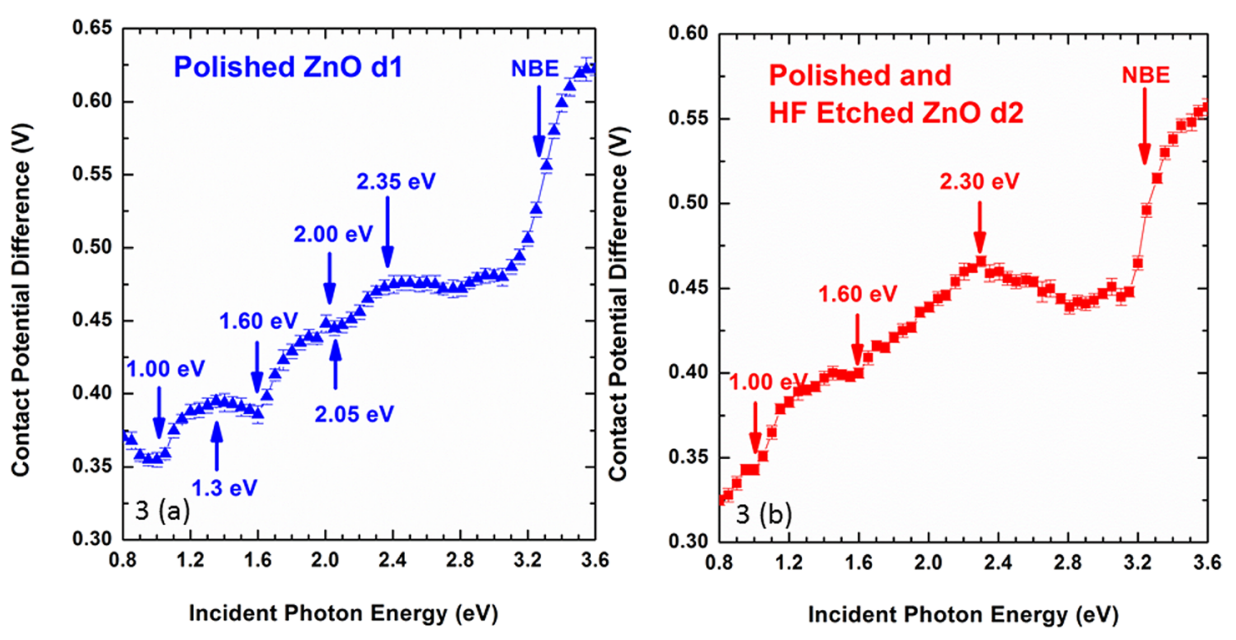

FIG. 3. SPS spectra of (a) mechanically polished $\mathrm{ZnO}$ sample $\mathrm{d} 1$ and (b) subsequent $\mathrm{HF}$ etched $\mathrm{ZnO}$ sample d2. $\mathrm{HF}$ etching removes $2.0 / 2.05 \mathrm{eV}$ and reduces $1.3 \mathrm{eV}$ defect features. 


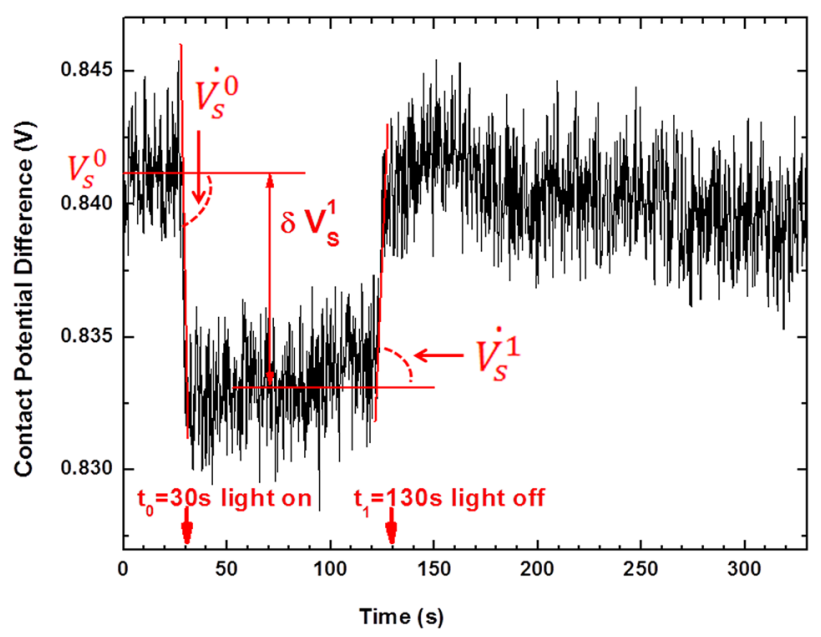

FIG. 4. T-SPS transient at $2.3 \mathrm{eV}$ of polished and $\mathrm{HF}$ etched $\mathrm{ZnO}$ showing parameters for Eq. (2).

TABLE I. Transient SPS defect densities calculated for each defect level using Eq. (2).

\begin{tabular}{lcc}
\hline \hline Sample & $\mathrm{E}_{\mathrm{C}}-1.0 \mathrm{eV}\left(\mathrm{cm}^{-2}\right)$ & $\mathrm{E}_{\mathrm{C}}-1.3 \mathrm{eV}\left(\mathrm{cm}^{-2}\right)$ \\
\hline Polished $\mathrm{ZnO}(\mathrm{d} 1)$ & $5.31 \times 10^{10}$ & $1.44 \times 10^{11}$ \\
HF etched $\mathrm{ZnO}(\mathrm{d} 2)$ & $9.30 \times 10^{9}$ & $\mathrm{NA}$ \\
\hline \hline
\end{tabular}

for these sample according to $\mathrm{C}-\mathrm{V}$ measurement, ${ }^{20} V_{s}{ }^{0}$ is the initial surface potential without light in dimensionless units (normalized to $\mathrm{kT} / \mathrm{q}$ by a $40 \times$ factor), $\dot{V}_{s}^{0}$ is the rate of potential change with light on, and $\dot{V}_{s}^{1}$ is the rate of potential change with light off, as shown in Fig. 4. In order to change surface potentials under illumination, free carriers require an electric field to drift, as exists within the surface depletion region. A simple calculation of the depletion width derived from Poisson's equation,

$$
W=\sqrt{\frac{2 \varepsilon \times V_{b i}}{q N_{b}}}
$$

yields $139 \mathrm{~nm}$ for a built-in voltage $\mathrm{V}_{\mathrm{bi}}=1 \mathrm{~V} .{ }^{20}$ Converting areal defect densities $n_{t}^{0}$ obtained using T-SPS (Eq. (2)) and shown in Table I to volume densities over width $\mathrm{W}$ yields values shown in Table II can be compared with DLTS bulk trap densities assuming uniform distributions. For sample d1, there is remarkable agreement with the DLTS densities listed above, suggesting that T-SPS normalized by depletion widths can provide approximate bulk densities comparable to those measured by DLTS. For sample d2, the $139 \mathrm{~nm}$ depletion width results in bulk densities that are more than a factor of 2 too high. This difference may be due to the dramatically different spatial distributions of $\mathrm{E}_{\mathrm{C}}-1.0 \mathrm{eV}$ defects between d1 and d2. See Figs. 1(a) and 1(b).

TABLE II. Transient SPS defect densities converted to bulk densities using $\mathrm{W}=139 \mathrm{~nm}$.

\begin{tabular}{lcc}
\hline \hline Sample & $\mathrm{E}_{\mathrm{C}}-1.0 \mathrm{eV}\left(\mathrm{cm}^{-3}\right)$ & $\mathrm{E}_{\mathrm{C}}-1.3 \mathrm{eV}\left(\mathrm{cm}^{-3}\right)$ \\
\hline Polished $\mathrm{ZnO}(\mathrm{d} 1)$ & $3.82 \times 10^{15}$ & $1.03 \times 10^{16}$ \\
HF etched $\mathrm{ZnO}(\mathrm{d} 2)$ & $6.69 \times 10^{14}$ & $\mathrm{NA}$ \\
\hline \hline
\end{tabular}

In summary, we used DRCLS and SPS to characterize the nature and concentration of native point defects in $\mathrm{ZnO}$ induced by mechanical polishing, which produced surface/ subsurface damage, NRRCs, and $\mathrm{V}_{\mathrm{Zn}}-\mathrm{R}$ defects. Post-polish etching effectively removed and/or passivated the NRRC, $\mathrm{V}_{\mathrm{Zn}}-\mathrm{R}$ and $\mathrm{V}_{\mathrm{O}}-\mathrm{R}$ defects by forming neutral complexes and shallow donors. Both DRCLS and TSPS demonstrated that HF etching decreases the defect density by an order of magnitude, consistent with previous DLTS measurements. This correspondence not only calibrates DRCLS peak intensities with defect densities, but it also demonstrates the use of a non-contact AFM Kelvin probe to measure defect densities inside semiconductors such as $\mathrm{ZnO}$ without the need to deposit rectifying contacts.

The authors gratefully acknowledge support from the National Science Foundation Grant No. DMR-0803276 (Charles Ying) and the Norwegian Research Council through the NANOMAT and FRINATEK programs. We thank Professor Leeor Kronik (Weizmann Insitute, Rehovot, Israel) for valuable conversations.

${ }^{1}$ D. C. Look, Mater. Sci. Eng. B 80, 383 (2001).

${ }^{2}$ S. J. Pearton, D. P. Norton, L. Ip, Y. W. Heo, and T. Steiner, Prog. Mater. Sci. 50, 293 (2005).

${ }^{3}$ D. C. Look, J. W. Hemsky, and J. R. Sizelove, Phys. Rev. Lett. 82, 2552 (1999).

${ }^{4}$ A. Janotti and C. G. Van de Walle, Phys. Rev. B 76, 165202 (2007).

${ }^{5}$ S. Zhang, S.-H. Wei, and A. Zunger, Phys. Rev. B 63, 075205 (2001).

${ }^{6}$ J. Hu and R. G. Gordon, Mater. Res. Soc. Symp. Proc. 283, 891 (1993).

${ }^{7}$ A. Janotti and C. G. Van de Walle, Nature Mater. 6, 44 (2007).

${ }^{8}$ S. O. Kucheyev, J. E. Bradby, J. S. Williams, C. Jagadish, M. V. Swain, P. Munroe, and M. R. Phillips, Appl. Phys. Lett. 80, 956 (2002).

${ }^{9}$ J. E. Bradby, S. O. Kucheyev, J. S. Williams, C. Jagadish, M. V. Swain, P. Munroe, and M. R. Phillips, Appl. Phys. Lett. 80, 4537 (2002).

${ }^{10}$ Z. Takkouk, N. Brihi, K. Guergouri, and Y. Marfaing, Physica B 366, 185 (2005).

${ }^{11}$ V. Coleman, J. E. Bradby, C. Jagadish, and M. R. Phillips, Appl. Phys. Lett. 89, 082102 (2006).

${ }^{12}$ S. F. Chichibu, T. Onuma, M. Kubota, A. Uedono, T. Sota, A. Tsukazaki, A. Ohtomo, and M. Kawasaki, J. Appl. Phys. 99, 093505 (2006).

${ }^{13}$ J. Mass, M. Avella, J. Jiménez, M. Callahan, D. Bliss, and B. Wang, J. Mater. Res. 22, 3526 (2007).

${ }^{14}$ J. Mass, M. Avella, J. Jiménez, A. Rodríguez, T. Rodríguez, M. Callahan, D. Bliss, and B. Wang, J. Cryst. Growth 310, 1000 (2008).

${ }^{15}$ M. Avella, V. Hortelano, O. Martinez, J. Mass, J. Jiménez, B. Wang, P. Drevinsky, and D. Bliss, Phys. Status Solidi C 9, 1580 (2012).

${ }^{16}$ D. Lucca, D. Hamby, M. J. Klopfstein, and G. Cantwell, Phys. Status Solidi B 229, 845 (2002).

${ }^{17}$ D. W. Hamby, D. A. Lucca, and M. J. Klopfstein, J. Appl. Phys. 97, 043504 (2005).

${ }^{18}$ D. Lucca, C. Wetteland, A. Misra, M. Klopfstein, M. Nastasi, C. Maggiore, and J. Tesmer, Nucl. Instrum. Methods Phys. Res. B 219-220, 611 (2004).

${ }^{19}$ F. A. Selim, M. H. Weber, D. Solodovnikov, and K. G. Lynn, Phys. Rev. Lett. 99, 085502 (2007).

${ }^{20}$ V. Quemener, L. Vines, E. V. Monakhov, and B. G. Svensson, Appl. Phys. Lett. 99, 112112 (2011).

${ }^{21}$ Y. Dong, F. Tuomisto, B. G. Svensson, A. Yu. Kuznetsov, and L. J. Brillson, Phys. Rev. B 81, 081201(R) (2010).

${ }^{22}$ Z. Zhang, K. E. Knutsen, T. Merz, A. Yu. Kuznetsov, B. G. Svensson, and L. J. Brillson, Appl. Phys. Lett. 100, 042107 (2012).

${ }^{23}$ Z. Zhang, K. E. Knutsen, T. Merz, A. Yu. Kuznetsov, B. G. Svensson, and L. J. Brillson, J. Phys. D: Appl. Phys. 45, 375301 (2012).

${ }^{24}$ N. H. Nickel and K. Brendel, Phys. Rev. B 68, 193303 (2003).

${ }^{25}$ M. Hofmann, A. Hofstaetter, F. Leiter, H. Zhou, F. Henecker, B. K. Meyer, S. B. Orlinskii, J. Schmidt, and P. G. Baranov, Phys. Rev. Lett. 88, 045504 (2002). 
${ }^{26}$ N. Ohashi, T. Ishigaki, N. Okada, T. Sekiguchi, I. Sakaguchi, and H. Haneda, Appl. Phys. Lett. 80, 2869 (2002).

${ }^{27}$ E. V. Lavrov, J. Weber, F. Börrnert, C. G. Van de Walle, and R. Helbig, Phys. Rev. B 66, 165205 (2002).

${ }^{28}$ L. E. Halliburton, L. Wang, L. Bai, N. Y. Garces, N. C. Giles, M. J. Callahan, and B. Wang, J. Appl. Phys. 96, 7168 (2004).

${ }^{29}$ E.-C. Lee and K. J. Chang, Phys. Rev. B 70, 115210 (2004).

${ }^{30}$ M. G. Wardle, J. P. Goss, and P. R. Briddon, Phys. Rev. B 71, 155205 (2005).

${ }^{31}$ G. Brauer, W. Anwand, D. Grambole, J. Grenzer, W. Skorupa, J. Č́́žek, J. Kuriplach, I. Procházka, C. C. Ling, C. K. So, D. Schulz, and D. Klimm, Phys. Rev. B 79, 115212 (2009).

${ }^{32}$ Z. Zhang, D. C. Look, R. Schifano, K. M. Johansen, B. G. Svensson, and L. J. Brillson, J. Phys. D: Appl. Phys. 46, 055107 (2013).

${ }^{33}$ S. F. J. Cox, E. A. Davis, S. P. Cottrell, P. J. C. King, J. S. Lord, J. M. Gil, H. V. Alberto, R. C. Vilão, J. Piroto Duarte, N. Ayres de Campos et al., Phys. Rev. Lett. 86, 2601 (2001).

${ }^{34}$ Y. M. Strzhemechny, H. L. Mosbacker, D. C. Look, D. C. Reynolds, C. W. Litton, N. Y. Garces, N. C. Giles, L. E. Halliburton, S. Niki, and L. J. Brillson, Appl. Phys. Lett. 84, 2545 (2004).

${ }^{35}$ B. K. Meyer, H. Alves, D. M. Hofmann, W. Kriegseis, D. Forster, F. Bertram, J. Christen, A. Hoffmann, M. Straßburg, M. Dworzak, U. Haboeck, and A. V. Rodina, Phys. Status Solidi B 241, 231 (2004).
${ }^{36}$ A. Shi, M. Stavola, S. J. Pearton, M. Thieme, E. V. Lavrov, and J. Weber, Phys. Rev. B 72, 195211 (2005).

${ }^{37}$ E. V. Monakhov, J. S. Christensen, K. Maknys, B. G. Svensson, and A. Yu. Kuznetsov, Appl. Phys. Lett. 87, 191910 (2005).

${ }^{38}$ H. Qiu, B. Meyer, Y. Wang, and C. Wöll, Phys. Rev. Lett. 101, 236401 (2008).

${ }^{39}$ E. V. Lavrov, F. Herklotz, and J. Weber, Phys. Rev. B 79, 165210 (2009).

${ }^{40}$ B. G. Svensson, T. M. Brseth, K. Johansen, T. Maqsood, R. Schifano, U. Grossner, J. Christensen, L. Vines, P. Klason, Q. Zhao et al., Mater. Res. Soc. Symp. Proc. 1035 (2008).

${ }^{41}$ L. Vines, E. Monakhov, R. Schifano, W. Mtangi, F. D. Auret, and B. Svensson, J. Appl. Phys. 107, 103707 (2010).

${ }^{42}$ D. Drouin, A. R. Couture, D. Joly, X. Tastet, V. Aimez, and R. Gauvin, Scanning 29, 92 (2007).

${ }^{43}$ T. A. Merz, D. R. Doutt, T. Bolton, Y. Dong, and L. J. Brillson, Surf. Sci. Lett. 605, L20 (2011).

${ }^{44}$ L. J. Brillson, Surfaces and Interfaces of Electronic Materials (WileyVCH, Weinheim, 2010), pp. 268-276.

${ }^{45}$ J. Lagowski, C. L. Balestra, and H. C. Gatos, Surf. Sci. 29, 203 (1972).

${ }^{46}$ J.-K. Lee, M. Nastasi, D. W. Hamby, and D. A. Lucca, Appl. Phys. Lett. 86, 171102 (2005).

${ }^{47}$ S. Zh. Karazhanov, E. S. Marstein, and A. Holt, J. Appl. Phys. 105, 033712 (2009).

${ }^{48}$ J. K. Dangbegnon, K. Talla, and J. R. Botha, Opt. Mater. 34, 920 (2012). 